\title{
Correction to: Improved Parent-Child Interactions Predict Reduced Internalizing Symptoms Among the Offspring of Parents with Bipolar Disorder Undergoing a Prevention Program: A Proof-of-Concept Study
}

\author{
Lisa Serravalle ${ }^{1}$. Vanessa lacono ${ }^{1} \cdot$ Alexa L. Wilson ${ }^{2} \cdot$ Mark Anthony Orlando $^{1} \cdot$ Virginia Tsekova $^{3}$. \\ Mark A. Ellenbogen ${ }^{1}$
}

Published online: 9 April 2021

(c) Springer Science+Business Media, LLC, part of Springer Nature 2021

\section{Correction to: Journal of Abnormal Child Psychology https://doi.org/10.1007/s10802-020-00743-3}

The original version of this article unfortunately contained a mistake. We notice an error in the information of the corresponding author. His email is correct, but the name is written as 'Mark Anthony Orlando' instead of 'Mark Ellenbogen'. The corrected corresponding author information is given below.

The original article has been corrected.

The original article can be found online at https://doi.org/10.1007/ s10802-020-00743-3

Mark A. Ellenbogen

mark.ellenbogen@concordia.ca

1 Centre for Research in Human Development, Concordia University, Quebec, Montreal, Canada

2 Department of Psychology, University of Montreal, Quebec, Montreal, Canada

3 Department of Psychology, Ryerson University, Toronto, Ontario, Canada
Publisher's Note Springer Nature remains neutral with regard to jurisdictional claims in published maps and institutional affiliations. 